\section{SOI: $1.1 /$ TAS DOI: $10.15863 /$ TAS International Scientific Journal Theoretical \& Applied Science}

\author{
p-ISSN: 2308-4944 (print) e-ISSN: 2409-0085 (online) \\ Year: $2018 \quad$ Issue: $03 \quad$ Volume: 59
}

Published: $30.03 .2018 \quad$ http://T-Science.org
Busharipa Kozhoyarovna Ukueva doctor of pedagogical sciences, acting professor of the department "General education disciplines and linguistic sciences" Osh State University, Osh, Kyrgyz Republic ossu.oms@gmail.com

SECTION 21: Pedagogy. Psychology. Innovations in the field of education.

\title{
ANALYSIS AND METHODS OF USING CREATIVE THINKING
}

Abstract: The article studies the development of creative thinking of students. The question of the influence of creative thinking on the further development of the student is considered. The problem of student s creative thinking in educational process of institution of higher education is revealed in the article. The concept of creative thinking is specified on the basis of theoretical analysis. The experience of work on the formation of student's creative thinking in chemistry teaching is given in the article.

Key words: method, analysis, thinking, education, philosophy, psychology, opportunity, observation.

Language: Russian

Citation: Ukueva BK (2018) ANALYSIS AND METHODS OF USING CREATIVE THINKING. ISJ Theoretical \& Applied Science, 03 (59): 210-212.

Soi: http://s-o-i.org/1.1/TAS-03-59-34 Doi: crossef https://dx.doi.org/10.15863/TAS.2018.03.59.34

УДК: 37.012.8(572.2)

\section{АНАЛИЗ И СПОСОБЫ ИСПОЛЬЗОВАНИЯ ТВОРЧЕСКОГО МЫШЛЕНИЯ}

Аннотация: В статье изучается развитие творческого мылиения студентов. Рассматривается вопрос влияния творческого мышления на дальнейшее развитие студента. $B$ статье актуализируется проблема творческого мышления студента в образовательном процессе вуза. Уточняется понятие «творческое мышление» на основе теоретического анализа. Представлен опыт работы по формированию творческого мышления студента в процессе обучения.

Ключевые слова: метод, анализ, мышление, образование, философия, психология, возможность, наблюдение.

\section{Introduction}

Студенты 1-го курса - это период выхода из подросткового возраста, становления самостоятельности. Как отмечается в психологии, в этот период студенты стараются вести себя как взрослые, растет интерес ко всему. Эта особенность наблюдения самого себя ведёт к возможности полнее познать свой нравственный, внутренний духовный мир и сделать из этого выводы. Так как, вчерашний учащийся школы, сегодня, как студент, заинтересован самостоятельно высказывать свое мнение перед сокурсниками и проявляет способность в стремлении к этому. Поэтому, также как философия и психология в европейском воспитании являются философской основой обучения $[5, \quad$ c.10], и в системе просвещения Кыргызстана нашим обязательным долгом является постоянно давать идейное направвление, не ограничиваясь только теоретическим обучением студентов, но и уделяя внимание на их психологическое состояние, обучая преимуществу этой психологической ситуации.

\section{Materials and Methods}

Профессор Гальперин замечая, что неумение студентов, только что переступивших порог школы, вначале творчески активно мыслить является одним из существенных недостатков в их психологии, отмечает, что единственный путь их устранения - это обучение умению использовать полученные знания на практике, чтобы они поверили в объективность, справедливость, правильность изучаемых явлений, не допуская, особенно на семинарских, практических занятия, возможности использовать штамповые словы, фразеологизмов 
[3, c.213]. Поэтому, первая задача - это формирование, прежде всего, логического мышления студентов. Так как при логическом мышлении у каждого студента, в соответствии с полученными знаниями, формируется отношение к жизненным явлениям, появляется возможность всестороннего анализа. Ученый О. Байгазиев связывает необходимость «развития мышления, эстетического вкуса, творческого отношения к работе, способностей, знаний личности" [1, с.58] через познание студентами бытия, мышления. Потому что, преподаватель, который знает, что в осмыслении реального бытия пробуждение "я", развитие самостоятельного мышления, обучение критическому отношению к окружающему, указывать путь в поисках истины, стимулирование эстетического азарта, активизация морального сознания, повышение духовно- эмоционального богатства, развитие художественного вкуса" [5, с.11] знает, что воспитанию надо обучать во взаимодействии с жизнью, чтобы мышление студента было масштабным и результативным, преподавателю необходимо достичь тесной взаимосвязи обучения и воспитания с жизнью. Потому как «культура разума и нравственная культура сопровождают, сопутствуют, дополняют друг друга и являются основой святых человеческих качеств", студент сознательно принимает, вникает, понимает, что преподает преподаватель и прилагает все усилия, чтобы получать знания. Следовательно, преподаватель, обучает, студентом размышляя, подводит итоги полученных знаний. И действительно, что их результаты, через тесную взаимосвязь мышления, обретут практическое доказательство.

В научно-методических источниках предлагают два пути комплексного изучения педагогических обстоятельств. Во-первых: анализировать несколько проблем на основе одного предмета, чем изучать суть. Во-вторых: намеченную проблему анализировать не по одному, а разным предметам. Например, используя намеченные нами новые технологии можно исследовать повышение творческой активности студентов по всем предметам, а не только на примере изучения истории новой кыргызской литературы. Так как, по мнению Н.Д.Талызина: "Комплексная активизация, обеспечивая путь к многоцелевым исследованиям, на основе изучаемых явлений, упрощает разделение претворяющих в жизнь отношений, и продолжает развивать ограниченные возможности второго плана, которые не относятся к решаемым проблемам [8, c.63]. Потому, что студенты, с первых студенческих дней, начинают овладевать процессом самопознания, иметь свое мнение, самостоятельно высказать свою точку зрения, отклонить мнения других. Поэтому основной проблемой является проведение занятий с начала учебного семестра первокурсников, изучив их психологию. Потому что в этом семестре преподаватель старается активизировать формирование психологических особенностей студентов в соответствии с требованиями ВУЗа, изыскивая, используя на занятиях разные пути, методики, технологии. Сначала А.А. Вербицкая показывает, что в этой ситуации надо:

> Давать студентам содержательные, понятные знания;

$>$ Обучить умению давать определение о понятом материале;

$>$ Уметь анализировать их;

$>$ Уметь различать значение одного понятия от другого;

$>$ Уметь обобщать из абстракции, разделять из обобщенного;

$>$ Передавать свои взгляды точно, доказательно, аргументированно;

$>$ Воспитывать умение самостоятельно делать выводы [2, с.37].

И педагог - психолог И.А.Зимняя предлагает обучить творческому критическому мышлению и самостоятельности через три ступени:

1. Преподаватель предлагает какую-то одну проблему (тему), разъясняет и доводит его суть до студентов;

2. Студенты, самостоятельно изыскивают пути донесения до аудитории понятые проблемы;

3. Студенты самостоятельно анализируют пройденную тему, дают им определение, используя различные методы, через новые технологии, которым обучил преподаватель [4, c.295], свои возможности, отмечают необходимость презентации новой темы аудитории. Применение таких новых технологий в обучении, как наиболее удобный прием, предлагают и Н.П. Зыдорожный, Т.М. Буйских, И.П. Валькова, И.А. Ниязовская.

Талант преподавателя играет основную роль в подаче направления, развивая творческое критическое мышление, деятельность студента. В. Левин отмечает, что эту особенность “следует постоянно развивать логическое мышление студентов, для развития их творческого критического мышления" [6, с.125]. Так как логическое мышление тесно связано с человеческой речью, без речи нет мышления. Мысль, которая появляется в голове, человек через речь передает другому. Поэтому речь инструмент общения человека, прямые реалии мысли. Так же как можно знать язык, не зная грамматики, можно логически мыслить, не зная логики, но в свое время А.М. Герцен, К.Д. Ушинский, русский ученый К.А. Тимирязев отметили, что логическая грамотность 
способствет повышению уровня мышления подобно тому, что не зная грамматики, нельзя грамотно писать.“У человека есть два вида мышления - это математическое и художественно-образное мышление" говорит В.А. Сухомлинский. Как известно мышление возникает только тогда, когда необходимо решить какую-то проблему. Чтобы выразить кому-то свое правильное мышление, ты должен предложить несколько решений по обсуждаемому вопросу. Если решений, которые ты желаешь кому-то пердложить, становится несколько или многовариантным, то можно отдалиться от достоверности и истины. Поэтому, чтобы в твоем мнении была достоверность, точность, надо подчиняться законам запоминания. В противном случае наше правильное мнение не дойдет до адресата. По данному вопросу в книге “Психология", изданной в издательстве "Юрайт" г. Москвы в 2005 году, отметив разные виды, типы запоминания, в связи с продолжительностью запоминания информации, подразделяют на кратковременное и долговременное сенсорное запоминание. Г. Эббингауз, позднее А. Миллер заметили, что продолжительность сенсорного или моментального запоминания достигает 1-2 секунд и рассматривается как итог какой-то моментальной активности, то особенностью кратковременного запоминания - это то, что информация сохраняется до 30 секунд. Несмотря на характерные особенности сохранившейся в памяти материала, величина запоминания равна $7 \pm 2$ и А. Миллер связывает магические свойства цифры 7 с особенностями в жизни и психике человека [7, с.203].
Различный иформационноый материал, в зависимости от характера запоминания, А.Н. Леонтьев делит на обоснованный, необоснованный, Л.С. Выготский - на прямой и израсходованный. Г. Эббингауз, с учетом характерных особенностей запомнившегося материала, делит на:

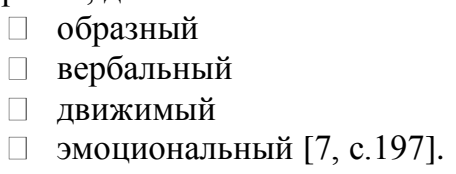

\section{Conclusion}

Как указано выше, в квалификациях запоминания, чем лучше человека, в том числе студента, запоминает, тем выше его мышление. Чем сильнее мышление, тем до более высокой точки деятельности достигается творческая активность студента в процессе использования новых технологий, сопровождается положительными результатами. Для этого, конечно, необходимо развивать их познание. Поскольку надо помнить, что познание, как вновь воображаемое явление истины в человеческом сознании не может быть ничем, кроме отражения объективного мира, что это предметы, их свойства, отношения в человеческом сознании. Психика человека, созданная в высшей степени материи - является одним из свойств головного мозга. Само это признание приводит к выводу, что между познанием-суждением и материальным миром никаких принципиальных ограничений нет и не может быть.

\section{References:}

1. Bajgaziev S.O., Rysbaev K S. (1989) «Pedagogikalyk tazhryjba» Izdenyyler zhana tazhryjbalar.[Tekst]. - F.: Mektep, 1989. -p.3058.

2. Verbickaja A.A. (1991) Aktivnye metody obuchenie $\mathrm{V}$ vysshej shkole: konteksnyj podhod. [Tekst]. M.: Anegnaja shkola, 1991. p.37-41.

3. Galperin P.Ja. (1976) Vvedenie v psihologiju [Tekst]. - M.: 1976. -p. 213.
4. Zimnjaja I.A. (1997) Pedagogicheskaja psihologija. [Tekst]. Rostov-na- Donu. Denisk, 1997. - p. 295.

5. (1982) Kratkij slovar' po filosofii. [ Tekst] - M.: Politizdat. 1982, - p. 10-14.

6. Levin M.M. (1968) Iskusstvo byt' drugim. [ Tekst] - M: 1968. -125 p.

7. (2005) "Psihologija". - M.: "Jurajt". - 2005. p.203.

8. Talyzina N.F. (2003) Pedagogicheskaja psihologija. [Tekst] - M: Akademija 2003. - p. 63. 